1 Institute of Health Services Management. Hospitals and Health Services Year Book 1986. London: IHSM, 1986.

2 Department of Health and Social Security. List of medical officers for environmental health and proper officers for environmental health matters. London: DHSS, 1986.

3 Department of Health and Social Security. NHS reorganization. London: DHSS, 1973. (HRC(73)34.)

4 Kapila M. Buttery R. Lessons from an outbreak of food poisoning at Stanley Royd Hospital: what are health authorities doing now? Br Med f 1986;293:321-2.

5 Committee of Inquiry into the Future Development of the Public Health Function. Public health in England. London: HMSO, 1988. (Cmnd 289.) (Acheson Report.)

(Accepted 11 November 1987)

Department of Community Medicine, Cambridge Health Authority, Fulbourn Hospital, Cambridge CB1 5EF

MUKESH KAPILA, MSC, MRCGP, senior registrar

CELIA DUFF, $M A, B M$, registrar

Correspondence to: Dr M Kapila, Health Education Authority, 78 New Oxford Street, London WC1A 1AH.

\section{Infective endocarditis complicating tricuspid valve disease in the carcinoid syndrome}

A distinct form of heart disease has been described in patients with the carcinoid syndrome. Disease of the cardiac valves occurs as a late complication in about half of the patients. ${ }^{1}$ Though abnormal cardiac valves are more susceptible to infection than normal valves, we believe that no cases of infective endocarditis have been reported in association with carcinoid heart disease. We report a case of streptococcal endocarditis affecting a regurgitant and stenotic tricuspid valve in the carcinoid syndrome.

\section{Case history}

A 65 year old man presented with a six month history of increasing lassitude, weight loss of $6.4 \mathrm{~kg}$, and intermittent watery diarrhoea. He had a history of prostatectomy for a benignly enlarged prostate and hypertension controlled with bendrofluazide. He denied having had rheumatic fever. He had a ruddy complexion and was feverish. Lymphadenopathy and finger clubbing were absent. The pulse was regular, and blood pressure was $130 / 85 \mathrm{~mm} \mathrm{Hg}$. A harsh mid-systolic murmur was heard, maximal at the apex. The murmur had not been present one year previously. The liver was smooth and non-tender, and its lower edge was palpable two fingerbreadths below the costal margin. There was no splenomegaly. The cardiac murmur changed over several days, becoming maximal at the lower left sternal edge.

The white cell count was $13.8 \times 10^{9} / 1$ with $69 \%$ neutrophils. An electrocardiogram showed sinus rhythm with right ventricular hypertrophy, and there was slight prominence of the left border of the heart in a chest $x$ ray film. Serial blood cultures grew Streptococcus viridans. Echocardiography showed thickened tricuspid valve leaflets with doming of the septal leaflet compatible with tricuspid stenosis. The right atrium and right ventricle were dilated. Contrast two dimensional echocardiography suggested tricuspid regurgitation. No vegetations were seen on the tricuspid valve. The mitral valve was normal; the pulmonary valve was not visualised. Computed tomography of the abdomen showed an $8 \times 10 \mathrm{~cm}$ mass posterolaterally in the right lobe of the liver and multiple smaller low density areas throughout the liver, suggesting metastases. No primary tumour was identified. The urinary 5-hydroxyindole acetic acid excretion was $385 \mu \mathrm{mol} / 24 \mathrm{~h}$ (normal $10-45 \mu \mathrm{mol} / 24 \mathrm{~h}$ ), confirming the carcinoid syndrome.

Intravenous benzylpenicillin and gentamicin were given for six weeks. The patient's fever settled rapidly, and his cardiovascular state did not deteriorate. The diarrhoea and facial flushing, characteristic features of the carcinoid syndrome, were treated with oral chlorpheniramine maleate and cimetidine. This produced a prolonged period of normal bowel function, but the flushing, although improved, was incompletely abolished.

\section{Comment}

The carcinoid syndrome is a rare cause of acquired cardiac disease, causing predominantly right sided lesions, but valvular heart disease is a frequent finding. ${ }^{12}$ Not until 1954, however, was carcinoid heart disease recognised as part of the full clinical and pathological syndrome. ${ }^{2}$ Pathognomonic fibrous plaques cover the pulmonary and tricuspid valves, the endocardium of the right atrium and ventricle, and the intimal surfaces of the vessels draining the right ventricle. ${ }^{3}$ The commonest valvular lesions are tricuspid regurgitation and stenosis with mild pulmonary stenosis. ${ }^{4}$ The two dimensional echocardiographic features of carcinoid heart disease are distinctive: the tricuspid valve leaflets appear diffusely thickened, shortened, and stiff without evidence of commissural fusion.

Carcinoid tumours and their metastases grow slowly, and morbidity largely derives from their endocrine effects. Cardiac lesions progress slowly but can result in appreciable morbidity and mortality as congestive cardiac failure develops.' Intractable heart failure has been successfully treated by replacement of the tricuspid valve. ${ }^{5}$ We believe that the association of carcinoid heart disease and infective endocarditis has not been documented previously.

1 Roberts WC, Sjoerdsma A. The cardiac disease associated with the carcinoid syndrome (carcinoid heart disease). Am f Med 1964;36:5-34.

2 Thorssen A, Biorck G, Biorkman G, Waldenstrom J. Malignant carcinoid of the small intestine with metastases to the liver, valvular disease of the right side of the heart (pulmonary stenosis and tricuspid regurgitation without septal defects), peripheral vasomotor symptoms, bronchoconstriction, and an unusual type of cyanosis: a clinical and pathologic syndrome. Am Heart $f$ constriction, and
1954;47:795-817.

3 Ferrans VJ, Roberts WC. The carcinoid endocardial plaque: an ultrastructural study. Hum Pathol 1976;7:387-409.

4 Davis MK, Lowry PJ, Littler WA. Cross-sectional echocardiographic feature in carcinoid heart disease. Br Heart f 1984;51:355-7.

5 Sworn MJ, Edlin GP, Mcgill DAF, Mousley JS, Monro JL. Tricuspid valve replacement in carcinoid syndrome due to ovarian primary. Br Med f 1980;281:85-6.

(Accepted 9 November 1987)

Department of Medicine, Victoria Hospital, Kirkcaldy, Fife KY2 5AH

D G MENZIES, MB, MRCP, research fellow

I W CAMPBELL, MB, FRCP, consultant physician

Department of Medicine, Western General Hospital, Edinburgh EH4 2XU I R STARKEY, MB, MRCP, consultant cardiologist

Correspondence to: Dr Campbell.

\section{Inhibitory effects of ranitidine on flushing and serum serotonin concentrations in carcinoid syndrome}

Dramatic reductions in the frequency, duration, and intensity of flushing attacks in the carcinoid syndrome have been reported during combined treatment with $\mathrm{H}_{1}$ and $\mathrm{H}_{2}$ receptor antagonists. ${ }^{12}$ We report a patient with a metastatic pancreatic carcinoid tumour in whom administration of ranitidine alone lead to cessation of flushing attacks, together with a significant reduction in serum serotonin concentrations.

\section{Case report}

A 73 year old man was admitted with flushing, and nausea and epigastric pain after meals. Physical examination showed no abnormality. Laboratory investigations showed that he had non-insulin dependent diabetes as well as an appreciably raised serum concentration of carcinoembryonic antigen and increased neuron specific enolase, serum lactic acid dehydrogenase, and transaminase activities.

Ultrasound scan and computed tomogram of the abdomen and retroperitoneum showed a small nodule in the head of the pancreas $1 \mathrm{~cm}$ in diameter and a solitary liver mass $5 \mathrm{~cm}$ in diameter. Histological examination of needle biopsy specimens from both lesions showed a metastatic endocrine pancreatic tumour. Serum serotonin concentrations were measured using high performance liquid chromatography and electrochemical techniques as described by Korpi (normal range 0.03 to $0.20 \mathrm{mg} / \mathrm{l}){ }^{3}$ The concentrations of serotonin in the serum were above normal when he was not having a flushing attack, and repeated measurements varied between 0.80 and $1.0 \mathrm{mg} / \mathrm{l}$. During flushing attacks the concentration rose to $1.30 \mu \mathrm{g} / \mathrm{l}$. Because of his nausea and epigastric pain after meals gastroduodenoscopy was carried out and biopsy specimens taken. Histological examination showed non-specific haemorrhagic gastritis and superficial ulceration in the duodenal bulb for which he was given ranitidine $150 \mathrm{mg}$ orally twice daily.

This treatment resulted in immediate cessation of his flushing attacks.

We therefore carried out a single blind crossover study of ranitidine $150 \mathrm{mg}$ orally twice daily followed by three days when he received only antacids (the placebo period was limited to three days for ethical reasons) and then a further period when he received ranitidine as before. The frequency of flushing attacks was recorded and serum serotonin concentrations were measured daily.

The results are shown in the figure. There was immediate cessation of flushing during both periods of ranitidine administration and recurrence of symptoms during the placebo period. The serum serotonin concentration fell as soon as he started taking ranitidine. During the placebo period there was a progressive rise to pretreatment values. One tailed unpaired analysis by the Mann-Whitney test showed that serum serotonin concentrations were significantly lower when he was receiving ranitidine than when he was receiving placebo $(\mathrm{p}<0.05)$. 